\title{
Cytotoxicity and Pro-inflammatory Properties of Aliphatic Alpha, Beta-unsaturated Acid and Ester Monomers in RAW264.7 Cells and Their Chemical Reactivity
}

\author{
YUKIO MURAKAMI, AKIFUMI KAWATA, SEIJI SUZUKI and SEIICHIRO FUJISAWA \\ Division of Oral Diagnosis and General Dentistry, Department of Diagnostic and Therapeutic Sciences, \\ Meikai University School of Dentistry, Sakado, Japan
}

\begin{abstract}
Background/Aim: $\alpha, \beta$-Unsaturated ester monomers such as methyl methacrylates (MMA), 2-hydroxyethyl methacrylates (2-HEMA), ethyleneglycol dimethacrylate (EGDMA) and triethyleneglycol dimetacrylate (TEGDMA) have been widely used in dentistry as dental materials. The present study was designed to clarify the proinflammatory activity of monomers. Materials and Methods: The cytotoxicity of the monomers and their effects on the expression of cyclooxygenase-2 (Cox2), nitric oxide synthase 2 (Nos2) and heme oxygenase 1 (Ho-1) mRNAs in RAW264.7 cells were determined using a cell counting kit and real-time reverse transcriptase-polymerase chain reaction, respectively. Results: The cytotoxicity declined in the order $n$-butyl acrylate $(n B A)>$ acrylic acid $>$ TEGDMA $>$ EGDMA $>$ methacrylic acid $\approx 2$ HEMA > lauryl methacrylate $>n B M A>M M A$. $n B A$ and EGDMA at $1 \mathrm{mM}$ up-regulated the expression of Cox $2 \mathrm{mRNA}$. In contrast, $1 \mathrm{mM} \mathrm{nBA}$ and $10 \mathrm{mM}$ 2-HEMA up-regulated the expression of Nos 2 mRNA. Up-regulation of Ho-1 mRNA expression was found for $0.1 \mathrm{mM} \mathrm{nBA,1} \mathrm{mM}$ EGDMA and 2 mM TEGDMA. The electrophilicity, $\omega$ was calculated on the basis of the density function theory BLYP/6-31G*. Conclusion: $n B A$ and EGDMA with high $\omega$ values exerted potent proinflammatory activities. $n B A$, EGDMA and TEGDMA upregulated Ho-1 gene expression. Ho-1 gene activation of monomers may promote resistance of chemical carcinogenesis in biological systems.
\end{abstract}

This article is freely accessible online.

Correspondence to: Dr. Yukio Murakami, Division of Oral Diagnosis and General Dentistry, Department of Diagnostic and Therapeutic Sciences, Meikai University School of Dentistry, 1-1 Keyakidai, Sakado, Saitama 350-0283, Japan. Tel: +81 492855511, Fax: +81 492876657, e-mail: ymura@dent.meikai.ac.jp

Key Words: $\alpha, \beta$-Unsaturated acid and ester monomers, cytotoxicity, pro-inflammatory properties, RAW264.7 cells, Cox-2, Nos 2 and HO-1 mRNA, quantum chemical parameters. $\alpha, \beta$-Unsaturated acid and ester monomers, particularly methacrylates, are widely used clinically as polymer materials in the medical and dental fields. Especially in dentistry, methacrylate resins in air can produce low amounts of monomer residues when used in dentures, restorative resins and adhesives, thereby possibly exerting adverse effects such as cytotoxicity, skin sensitization, mutagenicity, carcinogenicity, respiratory allergy, and organ toxicity (1-4). The adverse effects of acrylates and methacrylates, as (meth)acrylate monomers, may be due to their ability to induce oxidative stress and promote covalent interactions with cellular nucleophiles such as proteins, histidine, lysine, glutathione (GSH) and DNA bases (5-9).

As detailed in the critical review of the toxicology of methacrylates by Borack et al. (1), the electrophilicity of methyl methacrylates (MMA) and related monomers has been evaluated using two different in silico analytical systems. One approach predicted the electrophilic index $(\omega)$ by modeling the rate constants of specific electrophilenucleophile reactions based on their ionization potential and electron affinity, which are quantified in terms of their lowest unoccupied molecular orbital (LUMO) energy ( $\left.\mathrm{E}_{\mathrm{LUMO}}\right)$ and highest occupied molecular orbital (HOMO) energy $\left(\mathrm{E}_{\mathrm{HOMO}}\right)(7,10,11)$. Increasing values of $\omega$ indicate increasing reactivity with nucleophiles. The second approach employed nuclear magnetic resonance (NMR) spectroscopy to characterize the electron density of the $\beta$-carbon of the (meth)acrylate $\alpha, \beta$-double bond (11). The magnitude of the NMR shift correlated with electrophilic reactivity. For example, a high correlation $\left(r^{2}=0.998\right)$ was found between the NMR results for 20 acrylates and methacrylates and their corresponding glutathione reactivities, in terms of the $\mathrm{k}_{\mathrm{GSH}}$ value $\left(\mathrm{k}_{\mathrm{GSH}}\right.$, glutathione, reactivity) (12).

On the basis of an in silico study, we recently reported that the cytotoxicity and pro-inflammatory properties of cinnamates, acrylates and methacrylates in terms of their ${ }^{13} \mathrm{C}$-NMR chemical shifts of $\beta$-carbon $\left(\delta C_{\beta}\right)$ are related to their $\delta C_{\beta}$ values (13). However, the mechanisms responsible 
Table I. Molecular formulas of aliphatic $\alpha, \beta$-unsaturated acid and ester monomers.

\begin{tabular}{ll}
\hline Monomer & Molecular formula \\
\hline n-Butyl acrylate & $\mathrm{CH}_{2}=\mathrm{CHCOO}\left(\mathrm{CH}_{2}\right)_{3} \mathrm{CH}_{3}$ \\
Methyl methacrylate (MMA) & $\mathrm{CH}_{2}=\mathrm{C}\left(\mathrm{CH}_{3}\right) \mathrm{COOCH}_{3}$ \\
n-Butylmethacrylate (nBA) & $\mathrm{CH}_{2}=\mathrm{C}\left(\mathrm{CH}_{3}\right) \mathrm{COO}\left(\mathrm{CH}_{2}\right)_{3} \mathrm{CH}_{3}$ \\
Lauryl methacrylates( LMA) & $\mathrm{CH}_{2}=\mathrm{C}\left(\mathrm{CH}_{3}\right) \mathrm{COO}\left(\mathrm{CH}_{2}\right)_{11} \mathrm{CH}_{3}$ \\
2-Hydroxyethy methacrylates (2-HEMA) & $\mathrm{CH}_{2}=\mathrm{C}\left(\mathrm{CH}_{3}\right) \mathrm{COOCH} \mathrm{CH}_{2} \mathrm{OH}$ \\
Ethyleneglycol dimethacrylate (EGDMA) & $\mathrm{CH}_{2}=\mathrm{C}\left(\mathrm{CH}_{3}\right) \mathrm{C}(\mathrm{O})-\mathrm{OCH}_{2} \mathrm{CH}_{2} \mathrm{OC}(\mathrm{O}) \mathrm{C}\left(\mathrm{CH}_{3}\right)=\mathrm{CH}_{2}$ \\
Triethyleneglycol dimethacrylate (TEGDMA) & $\mathrm{CH}_{2}=\mathrm{C}\left(\mathrm{CH}_{3}\right) \mathrm{C}(\mathrm{O})-\left(\mathrm{OCH}_{2} \mathrm{CH}_{2}\right) 3-\mathrm{OC}(\mathrm{O}) \mathrm{C}\left(\mathrm{CH}_{3}\right)=\mathrm{CH}_{2}$ \\
Acrylic acid & $\mathrm{CH}_{2}=\mathrm{CHCOOH}$ \\
Methacrylic acid & $\mathrm{CH}_{2}=\mathrm{C}\left(\mathrm{CH}_{3}\right) \mathrm{COOH}$ \\
\hline
\end{tabular}

for the cytotoxic and pro-inflammatory effects of monomers have not been sufficiently clarified.

In the present study, firstly we investigated the cytotoxicity of eight $\alpha, \beta$-unsaturated acid and ester monomers with a wide range of hydrophobicities, namely acrylic acid, nBA, methacrylic acid, MMA, nBMA, 2-HEMA, LMA, EGDMA and TEGDMA against RAW264.7 cells using a Cell Counting Kit-8 (CCK-8). Secondly, we investigated the stimulatory effects of these monomers on the mRNA expression of Nos2, Cox2 and Ho- 1 in RAW264.7 cells using real-time polymerase chain reaction. Thirdly, we calculated their quantum chemical parameters (chemical hardness, $\eta$; electronegativity, $\chi$; softness, $\sigma$ and electrophilicity, $\omega$ ) using a density functional theory (DFT) BLYP /6-31G* level. The causal relationship between the cytotoxicity/pro-inflammatory properties and quantum chemical parameters was then discussed.

\section{Materials and Methods}

Materials. Acrylic acid, methacrylic acid, nBA, nBMA, MMA, LMA, 2-HEMA, TEGDMA and EGDMA were purchased from Tokyo Kasei Co. (Tokyo, Japan). The chemical structures and molecular formulae of these compounds are shown in Table I. Solutions of these compounds were prepared by dissolving each of them in dimethyl sulfoxide, followed by dilution to the required concentrations using serum-free RPMI-1640 (Invitrogen Co., Carlsbad, CA, USA) as test samples. Fetal bovine serum (FBS) was obtained from HyClone (Logan, UT, USA). Porphyromonas gingivalis ATCC33277 lipopolysaccharide (LPS) was obtained from Wako Pure Chemical Industries (Osaka, Japan).

Cell culture. The murine macrophage-like cell line RAW264.7, obtained from Dainippon Sumitomo Pharma Biomedical Co. Ltd. (Osaka, Japan), was used. The cells were cultured to a subconfluent state in RPMI-1640 medium supplemented with $10 \%$ FBS at $37^{\circ} \mathrm{C}$ and $5 \% \mathrm{CO}_{2}$ humidified atmosphere, washed, and then incubated overnight in serum-free RPMI-1640. They were then washed again and treated with the test samples for assessment of cytotoxicity and subjected to real-time polymerase chain reaction.
Cytotoxicity. In brief, RAW264.7 cells $\left(3 \times 10^{4}\right.$ per well) were cultured in NUNC 96-well plates (flat-well-type microculture plates) $(100 \mu \mathrm{l})$ for $48 \mathrm{~h}$ and then incubated with acrylates and methacrylates at a concentration of $0.0001-100 \mathrm{mM}$ for $24 \mathrm{~h}$. The relative number of viable cells was then determined using a Cell Counting Kit-8 (CCK8) (Dojindo Co., Kumamoto, Japan) (14). Ten microliters of CCK-8 solution was added to each well of the plate and incubated for one $\mathrm{h}$, after which the absorbance was measured at $450 \mathrm{~nm}$ with a microplate reader (Biochromatic, Helsinki, Finland). Lethal dose 50, $\mathrm{LC}_{50}$ value was determined from the dose-response curves. Data are expressed as means of three independent experiments. Statistical analyses were performed using Student's $t$-test and one-way ANOVA.

Preparation of total RNA and real-time polymerase chain reaction $(P C R)$. The methods of total RNA preparation and real-time PCR have been previously described (15). In brief, RAW264.7 cells in NUNC 96flat-well-type microculture plates ( 105 cells per well) were incubated for $3.5 \mathrm{~h}$ with or without the acrylates or methacrylates at a concentration of 0.01-100 mM. Then their total RNA was isolated using a RNeasy Plus Micro Kit (Qiagen Japan Co. Ltd., Tokyo, Japan) in accordance with the instruction manual. cDNA was synthesized from $2 \mu \mathrm{g}$ of total RNA for each sample by random priming using a High Capacity RNA-to-cDNA Kit (Thermo Fisher Scientific Japan, Tokyo, Japan). Reaction mixtures without the reverse transcriptase were used as negative controls. An aliquot of each cDNA synthesis reaction mixture was diluted and used for real-time PCR quantification. An equal-volume aliquot of each cDNA was mixed, serially diluted, and used as a standard. TaqMan probes/primers for Cox2, Nos2, Ho- 1 and $18 s$ rRNA and the PCR enzyme mix for real-time PCR were purchased from Thermo Fisher Scientific Japan. Real-time PCR quantification was performed in triplicate using the GeneAmp Sequence Detection System 5700 software (Thermo Fisher Scientific Japan) in accordance with the instruction manual. The relative amount of target was calculated from standard curves generated in each PCR, and quantitative data with coefficients of variance of less than $10 \%$ were used for further analyses. Each calculated amount of mRNA was standardized by reference to that for $18 \mathrm{~s}$ rRNA. Data are expressed as means of three independent experiments. Statistical analyses were performed using Student's $t$-test and one-way ANOVA. Regression analysis was done with StatMate III (ATMS Co., Ltd., Tokyo Japan).

Computational chemistry. The lowest energy conformation determined using a Monte Carlo molecular mechanics conformational search using the MMFF force field was optimized using DFT method/B3LYP levels 
Table II. Calculated quantum mechanical parameters of HOMO energy $\left(E_{\text {HOMO }}\right)$, LUMO energy $\left(E_{L U M O}\right)$, hardness $(\eta)$, softness $(\sigma, 1 / \eta)$, electronegativity $(\chi)$ and electrophilicity $(\omega)$ for acrylates and methacrylates, $\alpha, \beta$-unsaturated carbonyl compounds and their ${ }^{13} C$-NMR chemical shifts of $\beta$ carbon $\left(\delta C_{\beta}\right)$.

\begin{tabular}{|c|c|c|c|c|c|c|c|}
\hline Monomer & $\underset{\mathrm{eV}}{\mathrm{E}_{\text {HOMO }}}$ & $\underset{\mathrm{eV}}{\mathrm{E}_{\text {LUMO }}}$ & $\begin{array}{c}\eta \\
\mathrm{eV}\end{array}$ & $\begin{array}{c}\sigma \\
\mathrm{eV}\end{array}$ & $\begin{array}{c}\chi \\
\mathrm{eV}\end{array}$ & $\begin{array}{l}\omega \\
\mathrm{eV}\end{array}$ & $\begin{array}{c}\delta \mathrm{C}_{\beta} \\
(\mathrm{ppm})^{\mathrm{a}}\end{array}$ \\
\hline Acrylic acid & -1.34562 & -7.57182 & 3.113 & 0.321 & 4.459 & 3.193 & 133.3 \\
\hline Methacrylic acid & -1.22162 & -7.28756 & 3.033 & 0.330 & 4.255 & 2.985 & 128.3 \\
\hline Ethyl acrylate & -1.15441 & -7.28756 & 3.096 & 0.323 & 4.289 & 2.971 & 130.24 \\
\hline 2-HEA & -1.21859 & -7.43356 & 3.107 & 0.322 & 4.326 & 3.011 & 130.40 \\
\hline nBA & -1.1372 & -7.32219 & 3.093 & 0.323 & 4.230 & 2.892 & 130.21 \\
\hline MMA & -1.0754 & -7.1584 & 3.112 & 0.321 & 4.068 & 2.659 & 125.23 \\
\hline 2-HEMA & -1.0219 & -7.23888 & 3.106 & 0.322 & 4.13 & 2.743 & 125.84 \\
\hline nBMA & -0.94139 & -7.1661 & 3.112 & 0.321 & 4.054 & 2.640 & 124.70 \\
\hline LMA & -0.93271 & -7.15819 & 3.113 & 0.321 & 4.045 & 2.629 & - \\
\hline TEGDMA & -1.0798 & -7.19528 & 3.058 & 0.327 & 4.138 & 2.716 & 125.5 \\
\hline EGDMA & -1.1752 & -7.34073 & 3.083 & 0.324 & 4.258 & 2.941 & 125.9 \\
\hline
\end{tabular}

aTaken from Ref. $(11,13,37)$. Parameters see Eqs 1-4.

with a $6-31 \mathrm{G}^{*}$ basis set in vacuo, and the electronic structures and geometry of the optimized target chemicals were obtained $(10,16)$.

The $\mathrm{E}_{\mathrm{LUMO}}$ and $\mathrm{E}_{\mathrm{HOMO}}$ were obtained from the ground state equilibrium geometries. All calculations were carried out using SPARTAN'10 for Windows (Wavefunction, Inc; Irvine, CA, USA). The $\eta, \sigma, \chi$ and $\omega$ values were calculated as follows:
$\eta=\left(\mathrm{E}_{\mathrm{LUMO}}-\mathrm{E}_{\mathrm{HOMO}}\right) / 2$
(Eq. 1)
$\sigma=1 / \eta$
(Eq. 2)
$\chi=-\left(\mathrm{E}_{\mathrm{LUMO}}+\mathrm{E}_{\mathrm{HOMO}}\right) / 2$
(Eq. 3)
$\omega=\chi^{2} / 2 \eta$
(Eq. 4)

\section{Results}

Quantum chemical parameters. Results are shown in Table II. The interaction of frontier orbitals (HOMO and LUMO) has been shown to play a role in chemical reactivity (9). In general, HOMO of the nucleophile reacts with LUMO of the electrophilic species (17), which typically acts as an electron acceptor in charge-transfer interactions (6). According to the Frontier Orbital Theory, adduct formation occurs when a soft nucleophile donates its highest-energy electrons to the empty lowest-energy orbital of a soft electrophile. Hence, the most relevant frontier orbital for electrophiles is the LUMO, whereas the HOMO is most important for nucleophiles. Molecules with a relatively small HOMO-LUMO energy gap $\left.\left(\mathrm{E}_{\mathrm{HOMO}}-\mathrm{E}_{\mathrm{LUMO}}\right) / 2, \eta \mathrm{Eq} .1\right)$ are generally reactive, while those with a relatively large value are generally not reactive.

The $\sigma$ value (Eq.2) is defined as the ease with which electron redistribution can take place during covalent bonding, and thus the softer the electrophile (i.e. the more negative the $\mathrm{E}_{\mathrm{LUMO}}$ value and the higher the $\sigma$ value), the more readily it will form an adduct by accepting an outer
Table III. Cytotoxicity of monomers and hydrophobicity $(\log P)$.

\begin{tabular}{lccc}
\hline Monomer & $\mathrm{LC}_{50}, \mathrm{mM}$ & $\log \mathrm{Pa}, \mathrm{b}$ & $\pi^{\mathrm{c}}$ \\
\hline Acrylic acid & $3.184 \pm 0.036$ & - & -0.53 \\
Methacrylic acid & $7.712 \pm 0.064$ & -0.01 & -0.01 \\
n-Butyl acrylate & $1.371 \pm 0.184$ & 1.82 & 1.73 \\
Methyl methacrylate & $17.785 \pm 0.275$ & 0.89 & 0.73 \\
n-Butyl methacrylate & $12.921 \pm 0.253$ & 2.1 & 2.29 \\
2-Hydroxyethyl methacrylate & $7.700 \pm 0.079$ & 0.83 & -0.55 \\
Lauryl methacrylate & $9.346 \pm 0.05$ & 5.28 & 6.45 \\
EGDMA & $6.768 \pm 0.111$ & 1.88 & - \\
TEGDMA & $5.151 \pm 0.053$ & 1.55 & - \\
\hline
\end{tabular}

aTaken from Ref. (38), b(39), and c(40), respectively.

shell (10). In the present study, we also investigated the relationship between the $\omega$ and $\delta C_{\beta}$ values for acrylic acid, methacrylic acid and (meth)acrylates (Table II), and derived the following equations (Eqs 5-7):

$$
\begin{aligned}
& \delta \mathrm{C}_{\beta}=-17.3(( \pm 1.6)-19.9( \pm 4.1) \\
& \mathrm{E}_{\mathrm{LUMO}}\left(\mathrm{n}=10, \mathrm{r}^{2}=075, p<0.01\right) \\
& \delta \mathrm{C}_{\beta}=38.5( \pm 1.3)+21.2( \pm 3.5) \\
& \chi\left(\mathrm{n}=10, \mathrm{r}^{2}=0.75, p<0.01\right)
\end{aligned}
$$$$
\text { Eq. } 5
$$

$\delta \mathrm{C}_{\beta}=85.0(( \pm 1.4)+14.9( \pm 2.7)$

$\omega\left(\mathrm{n}=10, \mathrm{r}^{2}=079, p<0.001\right)$

Eq. 7

These findings indicated that there is a moderately linear relationship between the $\omega$ and $\delta C_{\beta}$ value for monomers. The $\omega$ value is a higher-order parameter that combines softness with the $\chi$ value and represents a sensitive measure of electrophilic 

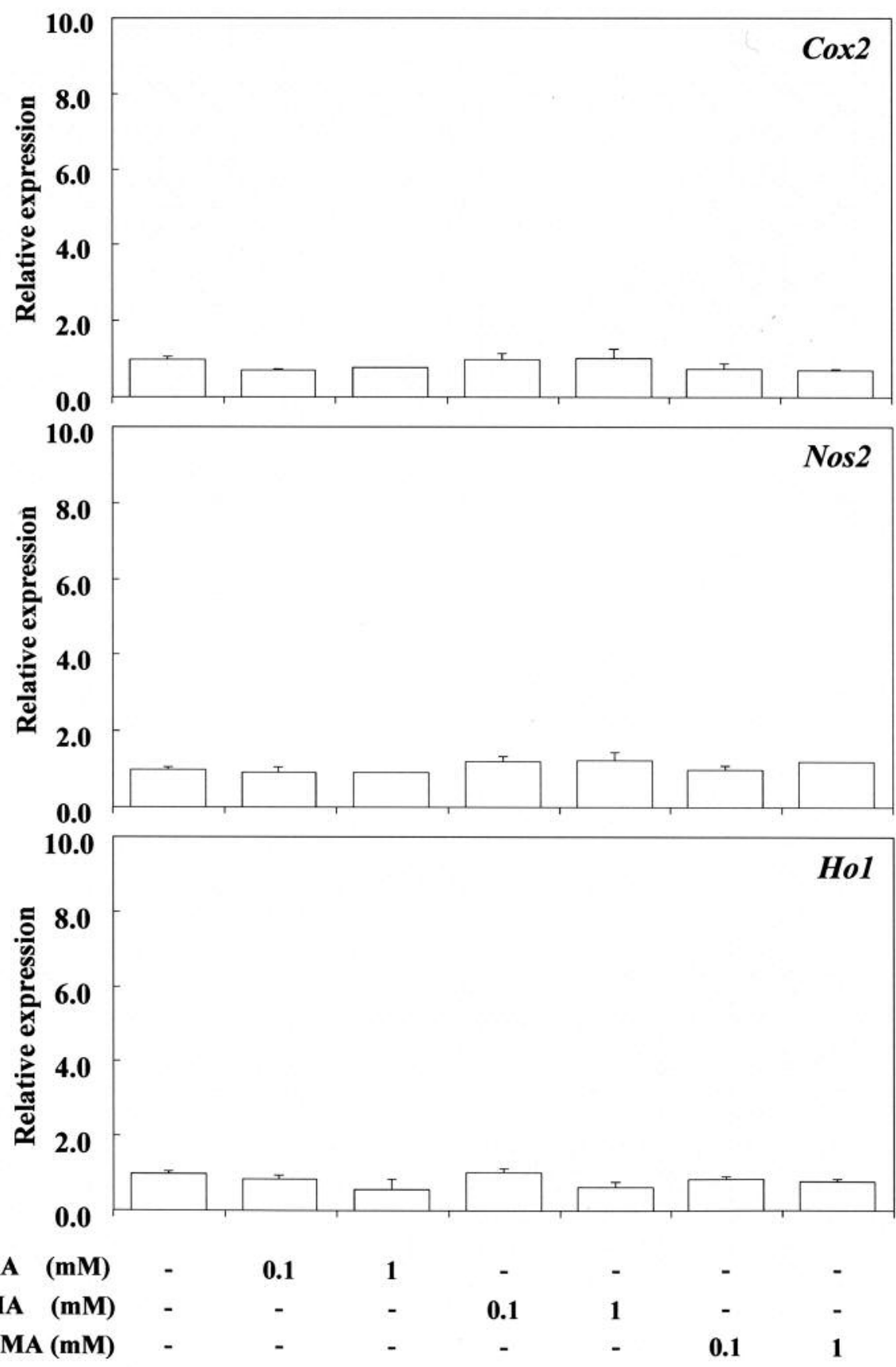

Figure 1. Stimulating effect of acrylic acid (AA), methacrylic acid (MA) and lauryl methacrylate (LMA) on cyclooxygenase-2 (Cox2), nitric oxide synthase 2 (Nos2) and heme oxygenase 1 (Ho1) gene expression in RAW264.7 cells. The cells were incubated for $3.5 h$ with each compound at a concentration of 0.1-1 mM, and then their total RNAs were prepared. Each cDNA was synthesized, and the expression level of each mRNA for Cox2, Nos 2 and Ho-1 was determined by real-time polymerase chain reaction and standardized against the expression of $18 s$ rRNA. The results are presented as means \pm standard error (SE) of three independent experiments, $S E<15 \%$. *Significantly different at $p<0.01 \mathrm{vs.} \mathrm{control} \mathrm{group.}$

reactivity. Enoch et al. have reported that the $\omega$ value has been used as a parameter of allergic dermatitis and allergic sensitization associated with $\alpha, \beta$-unsaturated carbonyl compounds (18). (Meth)acrylate monomers bind to endogenous proteins and their hapten effects may activate immune systems.
Cytotoxicity. The cytotoxicities of $\alpha, \beta$-unsaturated acids and ester monomers against RAW264.7 cells are shown in Table III. The cytotoxicity declined in the order $\mathrm{nBA}>$ acrylic acid $>$ TEGDMA $>$ EGDMA $>2$-HEMA $\approx$ methacrylic acid $>$ LMA $>$ nBMA $>$ MMA. 


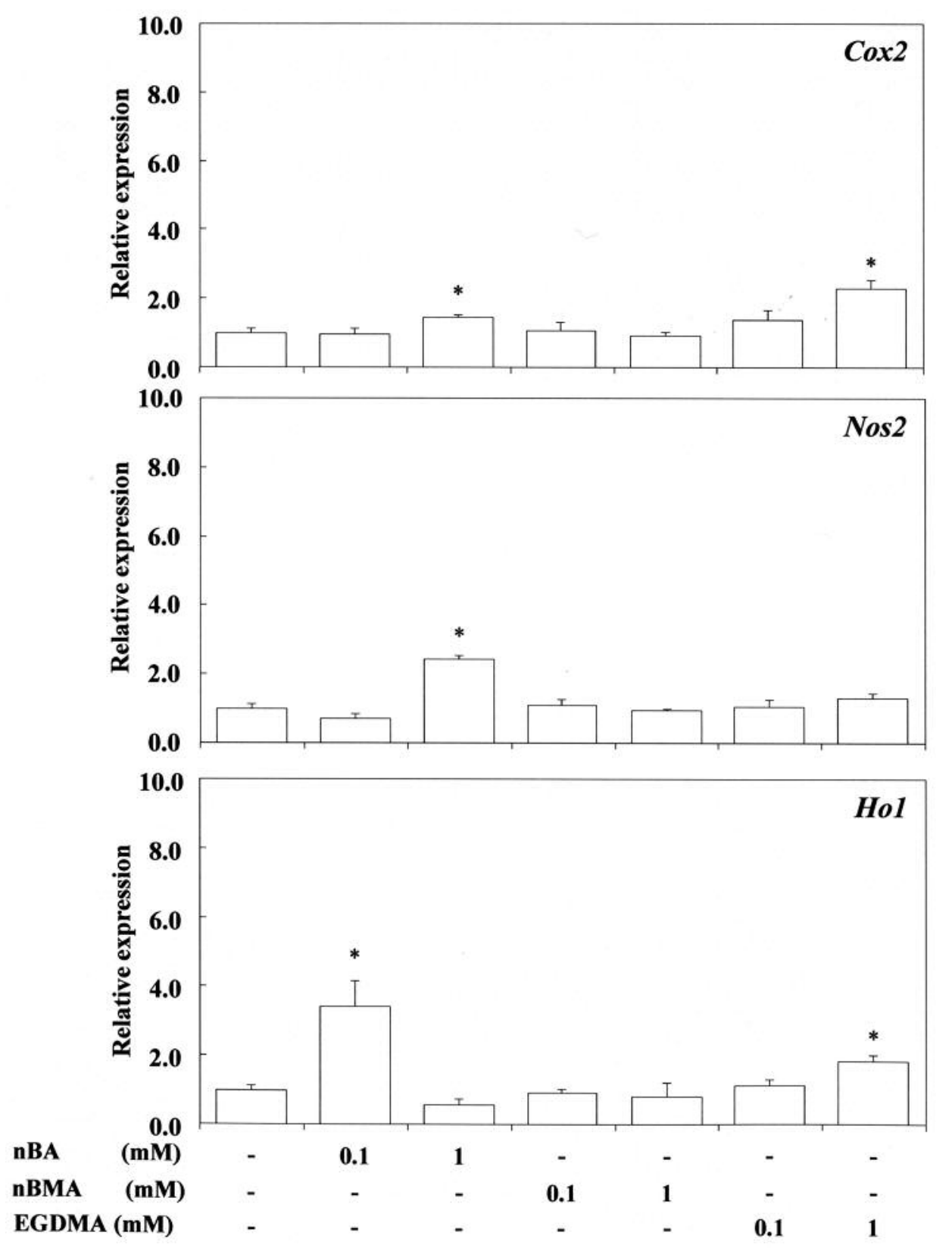

Figure 2. Stimulating effect of $n$-butyl acrylate (nBA), $n$-butyl methacrylate (nBMA) and ethyleneglycol dimethacrylate (EGDMA) on cyclooxygenase2 (Cox2), nitric oxide synthase 2 (Nos2) and heme oxygenase 1 (Ho1) gene expression in RAW264.7 cells. The cells were incubated for $3.5 \mathrm{~h}$ with each compound at a concentration of 0.1-1 mM, and then their total RNAs were prepared. Each CDNA was synthesized, and the expression level of each $m R N A$ for Cox2, Nos2 and Ho-1 was determined by real-time polymerase chain reaction and standardized against the expression of $18 s$ rRNA. The results are presented as means \pm standard error (SE) of three independent experiments, $S E<15 \%$. *Significantly different at p $<0.01$ vs. control group.

Except for acrylic and methacrylic acid, and two dimethacrylates, a significantly good relationship between the $\mathrm{LC}_{50}$ and $\omega$ value was observed as follows:

$\left(1 / \mathrm{LC}_{50}\right)=-6.4( \pm 0.1)+2.4( \pm 0.5)$

$\omega\left(\mathrm{n}=5, \mathrm{r}^{2}=0.87, p<0.05\right)$

Eq. 8
The cytotoxicity of mono(meth)acrylates was linearly related to the $\omega$ value. In contrast, there was no significant relationship between the cytotoxicity and $\log \mathrm{P}$ value.

Stimulation effects of monomers. Expression of Cox2, Nos2 and $H o-1$ mRNA in response to $0.1-1 \mathrm{mM}$ acrylic acid, 


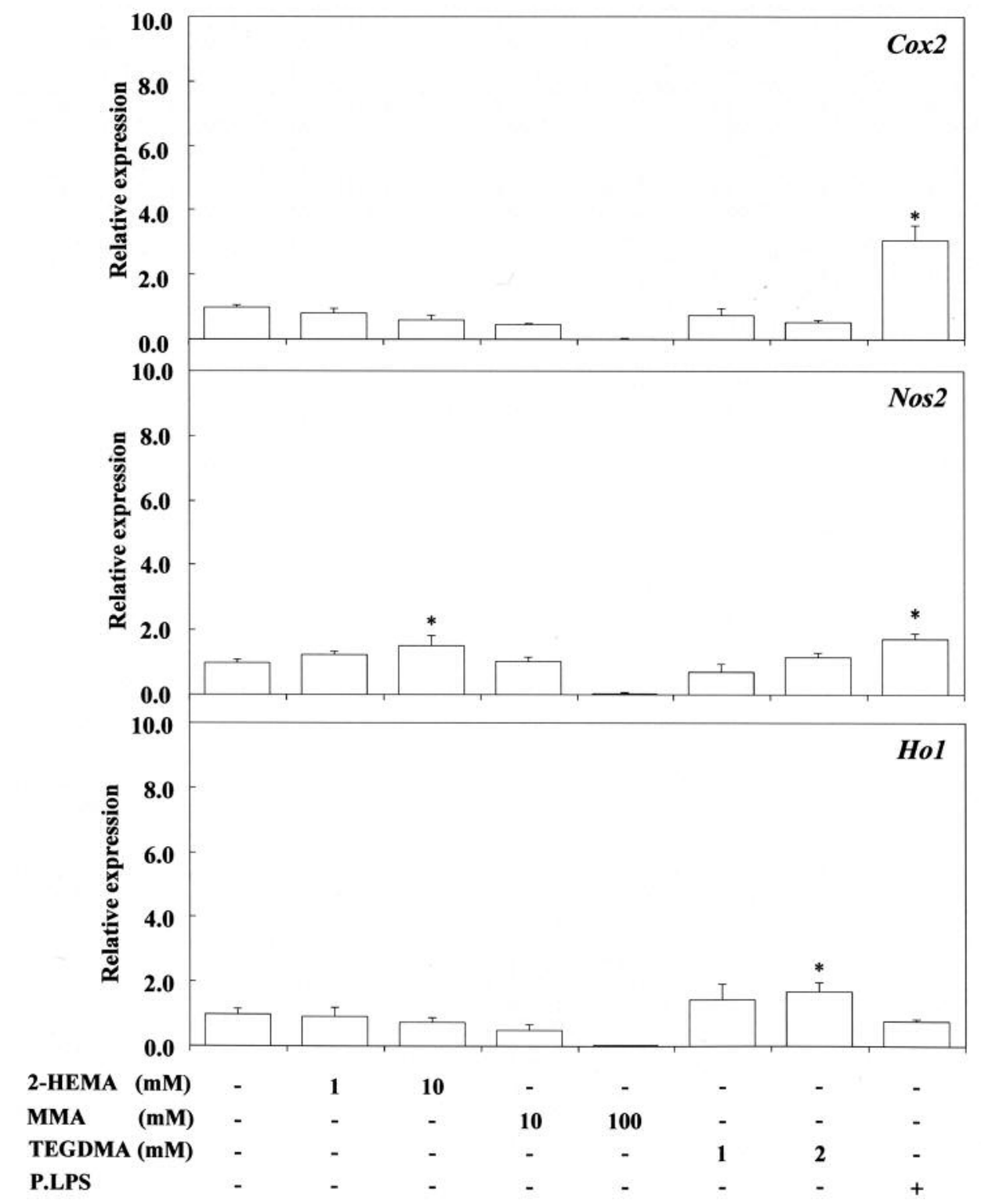

Figure 3. Stimulating effect of 2-hydroxyethyl methacrylate (2-HEMA), methyl methacrylate (MMA) and triethyleneglycol dimetacrylate (TEGDMA) on cyclo-oxygenase-2 (Cox2), nitric oxide synthase 2 (Nos2) and heme oxygenase 1 (Ho1) gene expression in RAW264.7 cells. The cells were incubated for $3.5 \mathrm{~h}$ with each compound at a concentration of 1-100 mM, and then their total RNAs were prepared. Each cDNA was synthesized, and the expression level of each mRNA for Cox2, Nos2 and Ho-1 was determined by real-time polymerase chain reaction and standardized against the expression of 18 s $r R N A$. The results are presented as means \pm standard error (SE) of three independent experiments, $S E<15 \%$. * $p<0.05 \mathrm{vs.} \mathrm{control} \mathrm{group.}$

methacrylic acid, and LMA, and in response to 0.1-1 $\mathrm{mM}$ nBA, BMA and EGDMA is shown in Figures 1 and 2, respectively. The corresponding responses to $2-100 \mathrm{mM} \mathrm{2-}$ HEMA, MMA and TEGDMA are shown in Figure 3, respectively.

EGDMA at $1 \mathrm{mM}$ and $\mathrm{nBA}$ at $0.1 \mathrm{mM}$ up-regulated Cox2 expression significantly, whereas 0.1-1 mM nBMA had no effect. In contrast, 0.1-1 mM acrylic acid, methacrylic acid,
nBMA and LMA did not up-regulate Cox2 expression. Also, 1-10 mM 2-HEMA and 10-100 mM MMA, and $2 \mathrm{mM}$ TEGDMA did not up-regulate Cox2 expression. In contrast, $1 \mathrm{mM} \mathrm{nBA}$ and $10 \mathrm{mM}$ 2-HEMA significantly up-regulated the expression of Nos 2 mRNA, whereas 1-2 mM TEGDMA and also 10 and $100 \mathrm{mM}$ MMA had no such effect. These findings in relation to TEGDMA and MMA differ from those reported previously (13), possibly due to differences in 
experimental conditions between the present and previous studies. nBA at $0.1 \mathrm{mM}$, EGDMA at $1 \mathrm{mM}$ and TEGDMA at $2 \mathrm{mM}$ significantly upregulated the expression of $\mathrm{Ho}-1$, whereas $0.1-1 \mathrm{mM}$ acrylic acid, methacrylic acid, nBMA and LMA, and $10 \mathrm{mM}$ MMA had no such effect. $P$. gingivalis LPS effectively elicited the expression of both Nos 2 and Cox2 mRNA, but did not elicit Ho- 1 gene expression, the value being similar to that of the control.

\section{Discussion}

Many reports have documented the local and systemic effects of unpolymerized methacrylates $(1,19)$. Yoshii (20) and Atsumi et al. (21) have reported that the cytotoxicity of (meth)acrylates against HeLa S3 cells, and salivary gland carcinoma cells (HSG) and human gingival fibroblasts (HGF) is related to their $\log$ P. Although highly effective for describing biological areas of structure-activity, $\log \mathrm{P}$ does not always precisely describe the link between chemical structure and biological activity. This is due to the fact that $\log \mathrm{P}$ comprises a number of components that relate to various aspects of molecular structure. The two most important components of solvation energy are electrostatic and polarization changes, and therefore it is assumed that log $\mathrm{P}$ comprises polarization, electrostatic, and electronic terms (22). The van der Waals area (VDW area) (molecular bulk) and HOMO energy (reactivity), but not $\mu$ (molecular polarity) of monomers widely used in dental materials have been linearly correlated with $\log \mathrm{P}(11)$. Chan and O'Brien (6) have reported that the cytotoxicity of 8 (meth)acrylates (methyl, 2-hydroxyethyl, ethyl, isobutyl and hexyl acrylate, and methyl, ethyl, isobutyl methacrylate) against hepatocytes is related significantly and linearly to their $\mathrm{k}_{\mathrm{GSH}}$ values, but that there is no relationship with $\log \mathrm{P}$, and also that the cytotoxicity of acrylates against hepatocytes is significantly related to the $\mathrm{E}_{\mathrm{LUMO}}$ value (6). A study on the relationships between hemolytic activity and quantum-chemical descriptors for 13 methacrylates has indicated that the hemolytic activity of aliphatics is related to the log P-term, whereas aromatic methacrylates with high hemolytic activity have a relationship with the $\omega$ term (11). The cytotoxicity of monomers may be dependent on cell species and the $\log \mathrm{P} / \omega$ activity of methacrylates. We have recently reported that proinflammatory and cytotoxic properties of (meth)acrylates may be related to their marked ability to act as Michael reaction acceptors, as estimated from the nuclear magnetic resonance (NMR) spectra of $\beta$-carbon using ${ }^{13} \mathrm{C}$-NMR spectra (13). In the present study, it was found that a relatively good linear relationship exists between the cytotoxicity and $\omega$ value of monoaliphatic monomers (Eq.8), except for two acid monomers and two dimethacrylates. Also, Eqs 5-7 suggested moderate relationships between $\delta C_{\beta}$ and the $\omega$ value of (meth)acrylates.
The $\mathrm{k}_{\mathrm{GSH}}$ values for various electrophilic Michael acceptors like acrylates and methacrylates have been investigated using various techniques $(6,23)$. GSH is the most important redox-regulatory non-enzymatic thiol available in cells and its antioxidant capacity is attributable to oxidation of the sulfhydryl group (-SH) in its cysteine residue. Also, GSH scavenges harmful ROS and protects against toxic xenobiotics in biological systems. The $\mathrm{k}_{\mathrm{GSH}}$ value (apparent second-order rate constant for the reaction of $\mathrm{GSH}, \mathrm{K}_{\mathrm{app}}$, liter $\mathrm{mol}^{-1} \mathrm{~min}^{-1}$ ) for ethyl acrylate, $\mathrm{nBA}$, MMA, ethyl methacrylates and EGDMA (as two independent esters) has been previously reported to be 52.0, $26.6,0.33,0.14$ and 0.83 , respectively (23), indicating a good relationship between the toxicity and $\mathrm{K}_{\mathrm{app}}$ for (meth)acrylates.

On the other hand, substrate-supported phospholipid bilayers serve as useful models for studying various properties of biological membranes. We have investigated the interaction of 4-methacryloxyethyl trimellitate anhydride (4-META), 4-methacryloyloxyethoxy carbonyl phthalic acid (4-MET), phthalic anhydride (PAN) and phthalic acid (PA) with multilamellar dipalmitoyl phosphatidylcholine (DPPC) liposomes, using NMR and differential scanning calorimetry (DSC), and found that the decreasing order of interaction at $\mathrm{pH} 7.4$ is 4-META > PAN > 4-MET > PA. In contrast, the interaction of acidic monomers such as 4-MET and PA with liposomes at $\mathrm{pH} 2.2$ has been greatly enhanced to that of corresponding anhydrides possibly owing to formation of hydrogen bonding between un-ionized carboxylate molecules and the phosphodiester head group of DPPC. Un-ionized acid monomers are more greatly hemolytic than ionized ones (24). In a similar context, to clarify the interaction mechanisms of various (meth)acrylate monomers with DPPC liposomes, the main phase transition temperature $\left(\mathrm{Tm},{ }^{\circ} \mathrm{C}\right)$ and enthalpy $(\Delta \mathrm{E}, \mathrm{kcal} / \mathrm{mol})$ of monomers have been determined using the DSC method (25); the interaction of monomer with liposomes has been characterized by the decrease in Tm and enthalpy value; the decreasing rank of Tm is $\mathrm{nBA}>$ EGDMA $>$ TEGDMA > 2-HEMA, acrylic acid $\approx$ methacrylic acid $>$ MMA. The Tm and $\triangle E$ of DPPC liposomes (control) is $41^{\circ} \mathrm{C}$ and $8.8 \mathrm{kcal} / \mathrm{mol}$, respectively.

nBA and EGDMA with the approx. half decrease in enthalpy shift $\mathrm{Tm}$ to lower temperature at approximately $10^{\circ} \mathrm{C}$ and also TEGDMA and 2-HEMA, and MMA with the approximately one-third of enthalpy shift $\mathrm{Tm}$ to the lower temperature at approx. 3 and $1^{\circ} \mathrm{C}$, respectively, as compared to the control value. Interestingly, water-soluble 2-HEMA exhibits a sharper DSC peak than the acrylic acid, methacrylic acid or control, suggesting that 2-HEMA shows a high cooperativity transition that is generally a characteristic of hydrophobic monomers (25). The interaction of 2-HEMA with liposomes is likely governed by the hydrophobic environment caused by the molecular 
association of the $\mathrm{OH}$ group of 2-HEMA (R-O-H ... O $(\mathrm{H})$ $\mathrm{R})$ in an aqueous medium (26). Also, acrylic acid and methacrylic acid may exhibit the high interaction with liposomes under acidic conditions due to the hydrophobic environment derived from molecular acid, but not ionic acid (24). Also, the interaction of EGDMA, TEGDMA and MMA with DPPC liposomes, as investigated using NMR, has indicated that the rank order of impregnation into liposomes is EGDMA > TEGDMA > MMA. The $\beta$-carbon and carbonyl carbon $(-\mathrm{C}(=\mathrm{O})-\mathrm{O}-)$ of monomer molecules, particularly the latter, are deeply impregnated into lipid bilayers (27). These findings suggest that the upregulation of Cox 2, Nos 2 or Ho- 1 gene expression in cells stimulated with nBA and EGDMA may be related to their large interaction potency with cellular lipid bilayers. Monomer-induced DSC phase transition properties have also been related to heat of formation, a quantum chemical parameter (28).

This liposome system is useful as an exploratory tool for providing insight into the biological function of the monomer structure (28). These findings may assist in the interpretation of the mechanism of monomer-induced cytotoxicity and proinflammatory activity. Lipid droplets (LDs) of (meth)acrylate monomers are essentially oil drops that are insoluble in water, and the impregnated monomers in cells are dispersed in the aqueous cytosol and may include associated proteins. It is now recognized that LDs move dynamically through the cytoplasm, interacting with other organelles, including peroxisomes, endosomes, endoplasmic reticulum (ER), the plasma membrane and mitochondria. These interactions are thought to facilitate the transport of lipids and proteins to other organelles. LDs are implicated in numerous physiological and pathophysiological functions (29).

On the other hand, cytotoxicity is determined by ester bond hydrolysis and enzymatic degradation of monomers. Carboxylesterase-mediated hydrolysis for the metabolism of related acrylate and methacrylate esters has also been demonstrated (30). Hydrolysis products from (meth)acrylates, acrylic acid and methacrylic acid may affect their cytotoxicity. Methacrylic acid and 2-HEMA may possibly be formed by hydrolysis of EGDMA. Hydrolysis of (meth)acrylates reduces their sensitization potential because, under physiological conditions, methacrylic and acrylic acids may be not electrophilic or protein reactive (21), since hydrophilic monomers such as acrylic acid, methacrylic acid and 2-HEMA exert less cytotoxicity against HSG and HGF cells. In contrast, in the present study, acrylic acid and methacrylic acid exerted relatively high cytotoxicity against RAW264.7 cells. The induction of cytotoxicity of acid monomers may depend on cell species and their nucleophilic addition activity to biological systems (9). Also, the important metabolic pathway for (meth)acrylates involves reaction with tissue nucleophiles via Michael addition on the electrophilic carbon of the $\beta$ unsaturated carboxyl group $(8,9)$. Eq.8 in terms of the $\omega$ value suggests that the cytotoxicity of mono(meth)acrylates may be related to Michael addition, which is likely a molecular mechanism for the toxicity of such monomers. The $\beta$-carbon of the double bond $(\mathrm{C}=\mathrm{C})$ can react with a nucleophilic center, i.e. amino or thiol groups in macromolecules, DNA, and proteins or thiols in small cellular molecules such as glutathione via Michael addition $(5,6,10)$; this may lead to adduct formation, an increase in glutathione disulfide (GSSG) and a decrease in GSH levels. Strong electrophilic monomers such as acrylates and dimethacrylates with two Michael reaction acceptors are liable to interact with nucleophilic - $\mathrm{SH}$ groups in proteins and DNAs in biological systems, resulting in cytotoxicity and apoptosis induction $(5,23)$.

It has been well documented that the inflammatory response to Eschericha coli and $P$. gingivalis LPS or $P$. gingivalis fimbriae involves the production of Cox2, Nos2 and proinflammatory cytokines such as tumor necrosis factor (Tnf)- $\alpha$, interleukin (IL)-6, and IL-1 $\beta$ in RAW264.7 cells (15, $16,31)$. In addition, anti-inflammatory properties of Ho-1 enzyme toward $P$. gingivalis LPS have been investigated (32).

Contrary to the pro-inflammatory effects of LPS, the inflammatory mediators Cox 2 and Nos 2 at both the protein and gene levels may also be expressed in macrophages stimulated by monomers. In our previous study, 2hydroxyethy acrylate (2-HEA) and ethyl acrylate (EA) were found to markedly elicit Cox2, Nos2 and Ho-1 gene expression in RAW264.7 cells (13). Taken together with the present findings, it seems that 2-HEA, EA, nBA and EGDMA with a high $\omega$ value of approximately $3 \mathrm{eV}$ (Table II) exert potent pro-inflammatory effects. These compounds also upregulate $\mathrm{Ho}-\mathrm{l}$ gene expression, suggesting that phase II metabolizing enzymes like $\mathrm{Ho}-1$ protect cells from oxidative stress. 2-HEMA at $10 \mathrm{mM}$ elicited Nos 2 gene expression but was not capable of eliciting $\mathrm{Ho}-\mathrm{l}$ expression, although 2HEMA has a moderately high $\omega$ value similar to that of TEGDMA (approx $2.7 \mathrm{eV}$ ). Thus, the $\mathrm{Ho}-1$ gene induction by TEGDMA may be related to its larger $\sigma$ value (approx. 0.33 $\mathrm{eV})$, relative to that of 2-HEMA $(0.32 \mathrm{eV})$ (Table II). In HepG2 cells, MMA but not 2-HEMA increases the antioxidant response element (ARE) at $30 \mathrm{mM}$, based on the reporter system used to examine ARE activity. Also, 2-HEMA, but not MMA, detectably reduced cellular GSH at $10 \mathrm{mM}$. This monomer has been reported to lower the cellular GSH level at $10 \mathrm{mM}$ and to augment ARE activity at $3 \mathrm{mM}$ (33). Also, Gallorini et al. (34) have reported that nuclear factor erythroid-2 (NF-E2)-related factor 2 (Nrf2), which is, under basal conditions, retained in the cytosol by the repressor protein and oxidative stress sensor, Kelch-like erythroid protein with cap'n collar (CNC) homology $(\mathrm{ECH})$-associated protein 1(Keap1) (35), is a major regulator of metabolic pathways activating cellular responses to maintain redox homeostasis in 2-HEMA-exposed cells; activation of the Nrf2regulated antioxidant cell response by $\mathrm{Nrf} 2$ activator can 
inhibit 2-HEMA-induced oxidative stress and support cell viability (34). Ho- 1 expression induced by monomers also varies according to cell species and monomer induction activity. Monomers with a relatively small $\omega$ value might exert inductive activity at higher concentrations. In our previous study, 2-HEMA, TEGDMA and MMA were not capable of suppressing the expression of Cox2, Nos 2 and Tnf- $\alpha$ mRNA in LPS-stimulated RAW264.7 cells and only 2-HEMA at 0.1 $\mathrm{mM}$ induced over-expression of Nos 2 mRNA (13). Although the reason for this is unclear, the present study suggested that Nos 2 gene induction by $10 \mathrm{mM}$ 2-HEMA may be involved. With regard to the bioactive effect of 2-HEMA, this compound is hydrolyzed to both methacrylic acid and ethylene glycol, and methacrylic acid is further oxidized to formaldehyde. 2-HEMA impairs the formation of phosphatidic acid, possibly by acylation of ethylene glycol released after 2-HEMA hydrolysis (36). The overexpression of Nos 2 mRNA induced by 2-HEMA in LPS-stimulated RAW264.7 cells may be due to the degradation products from this monomer. We have also reported previously that the DSC property of DPPC/cholesterol (CS) (10:1 molar ratio) liposomes shows a broad transition DSC peak at $38^{\circ} \mathrm{C}(\mathrm{Tm})$ with an enthalpy, $\Delta \mathrm{E}$, of $3.3 \mathrm{kcal} / \mathrm{mol}$. However, addition of 2-HEMA to DPPC/CS liposomes can effectively extract CS from such liposomes in a dose-dependent manner, and the DSC peak of DPPC/CS liposomes in the presence of 2-HEMA reverts to that of the original DPPC liposomes ( $\left.\mathrm{Tm} 40.5^{\circ} \mathrm{C} ; \Delta, 8.8 \mathrm{kcal} / \mathrm{mol}\right)$. 2-HEMA may be capable of interacting with $\mathrm{CS}$ in lipid bilayers of cellular membranes (26).

It is well known that antioxidant and electrophilic reagents enhance the transcription of phase II enzymes, including HO1 , superoxide dismutase, and catalase, via ARE present in the 5 '-flanking regions of their genes (35), and that the central transcription factor involved in ARE-mediated gene expression is Nrf2. In RAW264.7 cells exposed to nBA, EGDMA and TEGDMA, $\mathrm{Ho}-1$ expression was up-regulated at the transcriptional level as a response to oxidative stress. The ability of monomers to covalently bond with the nucleophile groups in proteins and other molecules may be related to not only their $\omega$ value but also their hydrophobicity $(\log P)$ or other forms of chemical reactivity, since water-soluble acrylic acid and methacrylic acid with high $\omega$ values did not affect gene expression. This suggests the influence of the $\sigma, \omega$ and $\log \mathrm{P}$ values of monomers, which represent a critical aspect of pro-inflammatory activity. As well as quantum chemical parameters and the $\log \mathrm{P}$ values of $\alpha, \beta$-unsaturated acid and ester monomers, their partitioning into lipid bilayers may represent a means of estimating their cytotoxicity and proinflammatory properties, as their activities initially depend on their interaction with cellular membranes. Further studies will be needed to clarify the mechanisms involved in the cytotoxicity and pro-inflammatory properties of $\alpha, \beta$ unsaturated acid and ester monomers in the dentistry field.

\section{Conclusion}

To clarify the mechanism(s) responsible for the cytotoxicity and pro-inflammatory activity of aliphatic monomers, we calculated their quantum chemical parameters $(\eta, \sigma, \chi$ and $\omega)$ using a DFT/BLYP $/ 6-31 G^{*}$ level. The $\mathrm{LC}_{50}$ of mono(meth)acrylates was linearly related to their $\omega$ value. Cox-2, Nos 2 and Ho- 1 expression levels in monomerstimulated RAW264.7 cells were potently elicited by nBA, followed by EGDM. These monomers both showed a high $\omega$ value. In contrast, no mRNA expression was elicited by monomers with a low $\omega$ value. Although water-soluble acrylic acid and methacrylic acid possess high $\omega$ values, these monomers had no effect on gene expression, possibly due to their hydrophobicity. EGDMA and TEGDMA, which are widely used in dentistry, are cytotoxic, but the oxidative stress they induce may be modulated via Ho-1 induction.

\section{Conflicts of Interest}

There are no conflicts of interests regarding this study.

\section{Authors' Contributions}

S. Fujisawa conceived the present idea. Y. Murakami verified the analytic methods. All Authors discussed and contributed to the final manuscript.

\section{Acknowledgements}

This work was supported by JSPS KAKENHI Grant Number JP15K11266 from the Ministry of Education, Science, and Culture of Japan. The Authors wish to thank Shigeru Ito for the quantum chemical calculations.

\section{References}

1 Borak J, Fields C, Andrews LS and Pemberton MA: Methyl methacrylate and respiratory sensitization: A critical review. Crit Rev Toxicol 41: 230-268, 2011. PMID: 21401327, DOI: $10.3109 / 10408444.2010 .532768$

2 Smith CK and Hotchkiss SAM: Xenobiotics as skin sensitizers: metabolic activation and detoxification, and protein-binding mechanisms. In: Allergic Contact Dermatitis: Chemical and Metabolic Mechanisms. Smith CK and Hotchkiss SAM (eds.). London, Taylor and Francis, pp. 119-205, 2005.

3 Stoeva I and Kisselova A: Allergic reactions to methacrylates in the dental practice: an overview of clinical and research literature. Dental Med 91: 80-85, 2009. PMID: 26557634, DOI: 10.7860/JCDR/2015/15640.6589

4 Johannsen FR, Vogt B, Waite M and Deskin R: Mutagenicity assessment of acrylate and methacrylate compounds and implications for regulatory toxicology requirements. Regul Toxicol Pharmacol 50: 322-335, 2008. PMID: 18346829, DOI: 10.1016/j.yrtph.2008.01.009

5 Krifka S, Spagnuolo G, Schmalz G and Schweikl H: A review of adaptive mechanisms in cell responses towards oxidative 
stress caused by dental resin monomers. Biomaterials 34 : 45554563, 2013. PMID: 23541107, DOI: 10.1016/j.biomaterials. 2013.03.019

6 Chan K and O'Brien PJ: Structure-activity relationships for hepatocyte toxicity and electrophilic reactivity of alpha,betaunsaturated esters, acrylates and methacrylates. J Appl Toxicol 28: 1004-1015, 2008. PMID: 18615533, DOI: 10.1002/jat.1366

7 Wondrousch D, Böhme A, Thaens D, Ost N and Schüürmann G: Local electrophilicity predicts the toxicity-relevant reactivity of Michael acceptors. J Phys Chem Lett 1: 1605-1610, 2010. DOI: 10.1021/jz100247x

8 Frederick $\mathrm{CB}$ and Reynolds $\mathrm{CH}$ : Modeling the reactivity of acrylic acid and acrylate anion with biological nucleophiles. Toxicol Lett 47: 241-247, 1989. PMID: 2749769

9 Osman R, Namboodiri K, Weinstein H and Rabinowitz JR: Reactivities of acrylic and methacrylic acids in a nucleophilic addition model of their biological activity. J Am Chem Soc 110: 1701-1707, 1988. DOI: 10.1021/ja00214a007

10 LoPachin RM, Gavin T, Geohagen BC and Das S: Neurotoxic mechanisms of electrophilic type-2 alkenes: soft soft interactions described by quantum mechanical parameters. Toxicol Sci 98 561-570, 2007. PMID: 17519395, DOI: 10.1093/toxsci/kfm127

11 Ishihara $\mathrm{M}$ and Fujisawa S: A structure-activity relationship study on the mechanisms of methacrylate-induced toxicity using NMR chemical shift of beta-carbon, RP-HPLC $\log$ P and semiempirical molecular descriptor. Dent Mater J 28: 113-120, 2009. PMID: 19280976

12 Fujisawa $\mathrm{S}$ and Kadoma Y: Prediction of the reduced glutathione (GSH) reactivity of dental methacrylate monomers using NMR spectra - Relationship between toxicity and GSH reactivity. Dent Mater J 28: 722-729, 2009. PMID: 20019424

13 Murakami Y, Kawata A, Suzuki S and Fujisawa S: Cytotoxicity and pro-/anti-inflammatory properties of cinnamates, acrylates and methacrylates against RAW264.7 cells. In Vivo 32: 13091322, 2018. PMID: 30348683, DOI: 10.21873/invivo.11381

14 Ishiyama M, Miyazono Y, Sasamoto K, Ohkura Y and Ueno K: A highly water-soluble disulfonated tetrazolium salt as a chromogenic indicator for NADH as well as cell viability. Talanta 44: 1299-1305, 1997. DOI: 10.1016/S0039-9140(97)00017-9

15 Murakami Y, Kawata A, Seki Y, Koh T, Yuhara K, Maruyama T, Machino M, Ito S, Kadoma $\mathrm{Y}$ and Fujisawa S: Comparative inhibitory effects of magnolol, honokiol, eugenol and biseugenol on cyclooxygenase- 2 expression and nuclear factorkappa B activation in RAW264.7 macrophage-like cells stimulated with fimbriae of Porphyromonas gingivalis. In Vivo 26: 941-950, 2012. PMID: 23160676

16 Murakami Y, Kawata A, Ito S, Katayama T and Fujisawa S: The radical scavenging activity and cytotoxicity of resveratrol, orcinol and 4-allylphenol and their inhibitory effects on Cox-2 gene expression and Nf-kb activation in RAW264.7 cells stimulated with Porphyromonas gingivalis-fimbriae. In Vivo 29: 341-349, 2015. PMID: 25977379

17 Lewis DF: Frontier orbitals in chemical and biological activity: quantitative relationships and mechanistic implications. Drug Metab Rev 31: 755-816, 1999. PMID: 10461548, DOI: 10.1081/DMR100101943

18 Enoch SJ, Madden JC and Cronin MT: Identification of mechanisms of toxic action for skin sensitisation using a SMARTS pattern-based approach. SAR QSAR Environ Res 19: 555-578, 2008. PMID: 18853302, DOI: 10.1080/ 10629360802348985
19 Gosavi SS, Gosavi SY and Alla RK: Local and systemic effects of unpolymerised monomers. Dent Res J (Isfahan) 7: 82-87, 2010. PMID: 22013462

20 Yoshii E: Cytotoxic effects of acrylates and methacrylates: relationships of monomer structures and cytotoxicity. J Biomed Mater Res 37: 517-524, 1997. PMID: 9407300

21 Atsumi T, Fujisawa S and Tonosaki K: (Meth)acrylate monomerinduced cytotoxicity and intracellular $\mathrm{Ca}(2+)$ mobilization in human salivary gland carcinoma cells and human gingival fibroblast cells related to monomer hydrophobicity. Biomaterials 27: 5794-5800, 2006. PMID: 16934868, DOI: 10.1016/ j.biomaterials.2006.07.041

22 Lewis DF and Broughton HB: Molecular binding interactions: their estimation and rationalization in QSARs in terms of theoretically derived parameters. ScientificWorldJournal 27: 1776-1802, 2002. PMID: 12806170, DOI: 10.1100/tsw.2002.343

23 McCarthy TJ, Hayes EP, Schwartz CS and Witz G: The reactivity of selected acrylate esters toward glutathione and deoxyribonucleosides in vitro: structure-activity relationships. Fundam Appl Toxicol 22: 543-548, 1994. PMID: 8056201

24 Fujisawa S and Kadoma Y: Hemolytic activity of a dental adhesive monomer and its interaction with dipalmitoyl phosphatidylcholine liposome NMR and DSC measurements. J Thermal Anal 51: 151-160, 1998. DOI: 10.1007/BF02719018

25 Fujisawa S, Kadoma Y and Masuhara E: A calorimetric study of the interaction of synthetic phospholipid liposomes with vinyl monomers, acrylates and methacrylates. J Biomed Mater Res 18: 1105-1114, 1984. PMID: 6544795, DOI: 10.1002/ jbm.820180912

26 Fujisawa S, Atsumi $\mathrm{T}$ and Kadoma Y: Cytotoxicity and phospholipid-liposome phase-transition properties of 2hydroxyethyl methacrylate (HEMA). Artif Cells Blood Substit Immobil Biotechnol 29: 245-261, 2001. PMID: 11358040

27 Fujisawa S, Kadoma Y and Komoda Y: Changes in NMR chemical shifts of methacrylates induced by their interactions with the phospholipid and the phospholipid/cholesterol liposome system. Dent Mater J 9: 100-107, 1990. PMID: 2098205

28 Fujisawa $\mathrm{S}$ and Kadoma Y: Mechanisms of action of (meth)acrylates in hemolytic activity, in vivo toxicity and dipalmitoylphosphatidylcholine (DPPC) liposomes determined using NMR spectroscopy. Int J Mol Sci 13: 758-773, 2012. PMID: 22312284, DOI: 10.3390/ijms13010758

29 Gross DA and Silver DL: Cytosolic lipid droplets: from mechanisms of fat storage to disease. Crit Rev Biochem Mol Biol 49: 304-326, 2014. PMID: 25039762, DOI: $10.3109 /$ 10409238.2014.931337

30 McCarthy TJ and Witz G: Structure-activity relationships in the hydrolysis of acrylate and methacrylate esters by carboxylesterase in vitro. Toxicology 116: 153-158, 1997. PMID: 9020516

31 Murakami Y, Shoji M, Hanazawa S, Tanaka S and Fujisawa S: Preventive effect of bis-eugenol, a eugenol ortho dimer, on lipopolysaccharide-stimulated nuclear factor kappa B activation and inflammatory cytokine expression in macrophages. Biochem Pharmacol 66: 1061-1066, 2003. PMID: 12963494

32 Ryu EY, Park SY, Kim SG, Park DJ, Kang JS, Kim YH, Seetharaman R, Choi YW and Lee SJ: Anti-inflammatory effect of heme oxygenase-1 toward Porphyromonas gingivalis lipopolysaccharide in macrophages exposed to gomisins A, G, and J. J Med Food 14: 1519-1526, 2011. PMID: 22145771, DOI: $10.1089 / \mathrm{jmf} .2011 .1656$ 
33 Orimoto A, Suzuki T, Ueno A, Kawai T, Nakamura H and Kanamori T: Effect of 2-hydroxyethyl methacrylate on antioxidant responsive element-mediated transcription: a possible indication of its cytotoxicity. PLoS One 8: e58907, 2013. PMID: 23516576, DOI: 10.1371/journal.pone.0058907

34 Gallorini M, Petzel C, Bolay C, Hiller KA, Cataldi A, Buchalla W, Krifka S, Schweikl H. Activation of the Nrf2-regulated antioxidant cell response inhibits HEMA-induced oxidative stress and supports cell viability. Biomaterials 56: 114-128, 2015. PMID: 25934285, DOI: 10.1016/j.biomaterials. 2015.03.047

$35 \mathrm{Kim}$ J, Cha YN and Surh YJ; A protective role of nuclear factorerythroid 2-related factor-2 (Nrf2) in inflammatory disorders. Mutat Res 690: 12-23, 2010. PMID: 19799917, DOI: 10.1016/j.mrfmmm.2009.09.007

36 Schuster GS, Caughman GB and Rueggeberg FA: Changes in cell phospholipid metabolism in vitro in the presence of HEMA and its degradation products. Dent Mater 16: 297-302, 2000. PMID: 10831786

37 Hatada K, Kitayama T, Nishiura T and Shibuya W: Relation between reactivities of vinyl monomers and their NMR spectra. Curr Org Chem 6: 121-153, 2002. DOI: $10.2174 / 1385272$ 023374454
38 Fujisawa S and Masuhara E: Determination of partition coefficients of acrylates, methacrylates, and vinyl monomers using high performance liquid chromatography (HPLC). J Biomed Mater Res 15: 787-793, 1981. PMID: 7309762, DOI: 10.1002/jbm.820150603

39 Fujisawa $\mathrm{S}$ and Masuara E: Determination of hydrophobic parameters (log PHPLC) for methacrylates, initiators and miscellaneous compounds used in dentistry by high-performance liquid chromatography (HPLC). J Jan Soc Dent Appar Mat 22: 277-284, 1981

40 Lawrence WH, Bass GE, Purcell WP and Autian J: Use of mathematical models in the study of structure-toxicity relationships of dental compounds. I. Esters of acrylic and methacrylic acids. J Dent Res 51: 526-535, 1972. PMID: 4501289, DOI: $10.1177 / 00220345720510024701$

Received December 21, 2018

Revised January 21, 2019

Accepted January 22, 2019 